Thanks are also due to Professor R. D. Lockhart and his assistants in the Anatomy. Department for the criticism and help they gave with the anatomy and diagrams. '. Also to Dr. A. Lyall for the examination of saliva.

\title{
REFERENCES
}

Collins, E. T.-Brit. Jl. of Ophthal., Vol. XVI, pp. 1-20, 1932.

Cunningham's Anatomy, 8th edition, 1943.

DÁnv, W. E.-Arch. of Surg., Vol. XVIII, p. 687, February, 1929.

Dogiel.-Arch. of Mik. Anat., Vol. X, ii, p. 632, 1893.

DUKE-ELDER, W. S.-Brit. Jl. of Ophthal., Vol. XIV. p. 61, 1930.

Ford, F. R.-Arch. Neurol. and Psychiat., Vol. XXX, 1927-1933.

Gottesfeid, B. H. and LeavitT, F. H.-Arch. Neurol. and Psychiat., Vol.' XLVII, p. 314, February; 1942.

Gray's Anatomy, 28th edition, 1942.

VON GRAEFE.-Arch. f. Ophthal., Vol. I(L), p. 295, 1854.

LockHART, R: D.-Brit. Jl. Surg., Vol. XII, p. 558-560, 1925.

Mutch, J. R.-Brit. Jl. of Ophthal., Vol. XXIII, pp. 225-238, 1937.

Parsons, J. H.-Roy, Lond. Ophthal. Hosp. Rpts., Vol. XV, p. 81, 1909.

SAVIN; L. H:-Brit. Jl of Ophthal., Vol. XXIII, p. 479, 1939.

SjöGREN; H.-Modern Trends in Ophthalmology, London, 1940.

\section{VITAMIN P IN OPHTHALMOLOGY}

BY

\author{
W. R. MATHEWSON
}

EDINBURGH

IN two cases of ocular haemorrhage recently under treatment vitamin $\mathrm{P}$ was used with very satisfactory results.

In the forst case the patient had very extensive retinal haemorrhages and nasal and bladder haemorrhages, but on giving vitamin $P$ the nasal and bladder haemorrhages ceased, no fresh retinal haemorrhages occurred, and those present absorbed. He suffered from myelomata, and the nasal haemorrhage was characterised by large clots of blood and serum.

In the second case the patient had recurrent haemorrhage into the anterior chamber after extraction of a cataract, but on giving vitamin $P$ there was no recurrence, and the iris, which had become muddy, rapidly cleared. The eye, which was looking very unhealthy, rapidly took on a healthy tone. The patient improved greatly and rapidly in general appearance and mental agility when vitamin $\mathrm{P}$ was given.

\section{FIRST CASE-General History}

A University graduate of high intellectual attainment and regular life was first seen in 1935 at the age of 47 , and thereafter from time to time for refractive errors and the like:

\footnotetext{
* Received for publication, February 14, 1944
} 
In July, 1943, he fell very ill from multiple myeloma, and for this condition he received X-ray " spray treatment;" with a warning of the possibility of petechial haemorrhages.

About this time he suffered from bladder and nasal haemorrhages, but no local causes for these were diagnosed, though he was in hospital for thorough investigation.

The prognosis was considered to be hopeless at the time when vitamin $\mathbf{P}$ was commenced.

\section{Ophthalmological Notes}

What follows is a condensation from several visits, some to his bedside, for he was for a time too weak and jaundiced and short of breath to get up.

Many observations, such as field examination, were omitted because he was very ill, and to avoid drawing the patient's attention to his condition.

Onset.-(1) About August 12 he found himself unable to see to read. (2) Some days later he got out of bed, early in the morning, to shave, and had a sudden onset of severe headache, and after this, so far as can be ascertained, his general condition and his vision became worse. He did not remember this incident, but it was thought to have been a subarachnoid haemorrhage. The headache was temporal and mainly on the left side.

\section{First Ophthalmological Examination}

August 15, 1943.-Vision with glasses was R.E. J.2, L.E. J.6. Fundi: The right eye had much vascular engorgement and many haemorrhages. There were haemorrhages on the disc and nerve fibre layer haemorrhages medial to the disc, small round feathery edged haemorrhages above the macula, and a large subhyaloid haemorrhage below the macula. Patches of exudate were also present. At the macula there was a stippled area almost a quarter disc in diameter and noted as "leathery edged," for its edge looked like leather.

The left eye showed more extensive haemorrhages, and the appearance suggested, at first sight, central venous thrombosis.

Treatment.-Vitamin $\mathrm{P}$ was prescribed at this time.

\section{Further Ophthalmological Examination}

August.-Towards the end of August it was noted that some of the patches of exudate appeared to be absorbing, but that the veins and arteries were in places almost indistinguishable except by using a red-free filter on the ophthalmoscope, that they appeared in places empty and in others filled with an almost clear or translucent pinkish fluid, and looked as if buried in an oedema overlying the retinal surface. There were no fresh haemorrhages. 
The haemoglobin was down to 40 per cent. and the R.B.C. was about $2,000,000$ at this time.

September.-Dr. A. H. Sinclair kindly saw the case in consultation and confirmed the retinal conditions, and agreed that so far as coùld be determined they were associated with retinal venous thrombosis and subarachnoid haemorrhage.

In the right eye there was altitudinal hemianopia which appeared to be associated with the subhyaloid haemorrhage and diminished as this haemorrhage absorbed.

Later in the month some right homonymous hemianopia was detected and was still present in some degree in November, and was at the time thought to be connected with subarachnoid haemorrhage. The hemianopia was detected because the patient stated that on his tin of glucose he could now, binocularly, read the word "Glucodin," whilst previously he could read only " Gluco."

The fundi were now clear enough for it to be seen that the haemorrhages and exudates were in many cases in the region of arterio-venous crossings, an important point, and at some points the tributary veins could clearly be seen to be threadlike and empty.

Almost immediately after the commencement of administration, in August, of vitamin P, nasal and bladder haemorrhages ceased, and also, it is emphasized, there were no fürther retinal haemorrhages.

In September, however, there was a short period during which vitamin $P$ was omitted and nasal haemorrhage recommencedd, and this was considered to be one of the indications' that vitamin $\mathbf{P}$ was really having some therapeutic action.

Octaber.-Early in October Dr. Scarborough kindly arranged for the capillary permeability to be ascertained by his negative pressure method and by his apparatus, and it was found to be about 450 , the normal being about 300 , and haemorrhages from capillaries, it is to be noted, are liable to occur under 250 .

Haemoglobin now 64 per cent. and R.B.C. 2,760,000.

November.-Vitamin $\mathrm{P}$ had been commenced in August, 4 tablets of permidin (Glaxo) daily, and continued for six weeks, and then stopped early in October when the capillary permeability was 450. Early in November the capillary permeability was found to be below 250, after the vitamin $\mathrm{P}$ had been stopped for 20 days. Vitamin $\mathrm{P}$ administration was therefore recommenced, this time two tablets of rose hip (ovaltine) being given dàily.

The R.B.C. was now $3,900,000$ and the haemoglobin 74 per cent.

The left fundus appeared normal and the right fundus nearly so, and there were no fresh haemorrhages.

The patient's general condition was so much better that he was able to come into town for examination, and the following notes were made :- 
Right Eye. $-\mathrm{V}=6 / 18$ and there was difficulty with the letters towards the right side of the line of type, and iwith $-0.50 \mathrm{sph}$. $V=6 / 18$, and there was difficulty with the letters towards the right side of the line of type, and on adding $+2.25 \mathrm{sph}$., near vision was J.6.

The fundus showed a tributary to the superior temporal vein, previously noted as blocked, to be patent now. There seemed to be slight pigmentary changes at the macula, but this was not certain.

Left Eye. $-\mathrm{V}=6 / 12$ three letters, but not those towards the right side of the line of type, and with $\frac{0.00}{-0.50}$ at $90 \mathrm{deg} .6 / 12$, three letters, but not those at the right side of the line of type, and on adding +2.25 sph., near vișion was J.2.

From this it was argued that there was some slight homonymous hemianopia, but it was agreed that his attention should not be directed towards this by carrying out perimetric or Bjerrum's screen examination.

The fundus was normal, exćept that perhaps the disc edges were a little hazy, but this was not certain.

\section{Summary}

A patient with multiple myelomata of the type accompanied by profound anaemia was diagnosed as having subarachnoid haemorrhage, retinal venous thrombosis, and retinal haemorrhages.

Nasal and bladder haemorrhages were also present.

He had received X-ray " spray treatment." '

When vitamin $P$ was given the bladder and nasal haemorrhages ceased and there were no fresh retinal haemorrhages, but when the administration of vitamin $P$ was temporarily suspended in September the nasal haemorrhage recommenced, but ceased when administration of vitamin $P$ was recommenced; from which it is argued that vitamin $P$ might be having some therapeutic effect.

By November vision had greatly improved, but there was a homonymous hemianopic depression of the field of vision present. The fundi were practically normal to ophthalmoscopic examination, and showed nothing to account either for the vision still being subnormal or for the hemianopia.

\section{Comments}

It is difficult in this case to discriminate justly between reasonable deduction and speculation owing to lack of experience of some of the factors involved. Properly controlled scientific observation is indicated. 
It is considered fair to deduce from the evidence available that vitamin $P$ had/an effect in this case, influencirg the nasalhaemorrhage favourably, and presumably the retinal haemorrhage also, but further investigation is needed to confirm this.

The retinal haemorrhages and X-ray treatment.-No fresh retinal haemorrhages occurred after vitamin $P$ was given, one cannot definitely deduce that this was because of the vitamin $\mathbf{P}$, but only speculate.

One can fortify this argument by saying that in retinal venous thrombosis repeated haemotrhages do occur, but that, anyway in this case, in which vitamin $\mathrm{P}$ was given, they did not recur. This is still only probability, not proof.

Professor A. J. Ballantyne kindly remarked that the X-ray treatment would increase the capillary permeability, and one can speculate as to whether increased capillary permeability was connected with the subarachnoid and retinal haemorrhages.

$\mathrm{X}$-ray treatment is the only treatment known to influence multiple myelomata favourably, but one of the factors limiting the dosage may be the liability to haemorrhages following increased capillary permeability as a result of the application of the X-rays.

There are no data to show whether, in the present case, there was increased capillary' permeability associated with the disease itself, and present before, and independently of, any X-ray treatment, or what the capillary permeability was before and after the X-ray treatment.

But it is suggested that in future cases of multiple myelomata the capillary permeability could be ascertained before $\mathrm{X}$-ray treatment was commenced; and it has been suggested to me that by giving vitamin ' $\mathrm{P}$ before $\mathrm{X}$-ray treatment, and also, of course, during and after it, the capillary permeability could be so controlled as to lessen the danger, of haemorrhage after X-rays, and so enable higher X-ray dosage to be used. This could be done in other conditions besides myelomata, in which $\mathrm{X}$-ray treatment is being given.

So far as it has been possible to judge, it would appear that vitamin $P$ has been beneficial therapeutically, and might be beneficial prophylactically, in cases where $\mathrm{X}$-ray treatment is involved.

The question of subarachnoid haemorrhage.-The evidence might seem a little slender. The diagnosis was made before the existence of homonymous hemianopia was known, and was largely on the grounds of sudden headache and retinal haemotrhages, and may be compared with Professor A. J. Ballantyne's cases in the Brit. Jl. of Ophthal., September, 1943.

The hemianopia was discovered late in the course of the illness, and associated with loss of memory suggests cerebral thrombosis or haemorrhages rather than subarachnoid haemorrhàge. 
There are times when one hesitates to make an out-of-the-way diagnosis and, in this connection, I clearly remember a patient with bilateral thrombosis, when in charge of the Eye Department at the Metropolitan Hospital, London, and of waving a white towel in front of her to see if she could see it. I passed the case on to Dr. C. Worster-Drought, who showed it at the Royal Society of Medicine. (See Bilateral Occipital Thrombosis, Proceedings of Royal Society'of Medicine, July, 1928, Section of Neurology.)

In presenting this case an attempt has been made to show it as it grew and developed, rather than to give a summary, though this would have been shorter, of the final findings.

In this connection the fields taken in February, when the patient requested it; are instructive, first of all as showing how far the bedside diagnosis of hemianopia was correct or permanent, and secondly, in connection with the nature of central scotoma in




anaemia, as mentioned in the Brit. Jl. of Ophthal., December, 1943 , page 541.

The perimeter fields for white objects were normal.

The Bjerrum's Screen showed for the right eye with white discs bàring of the blind spot and a central scotoma with a nucleus.

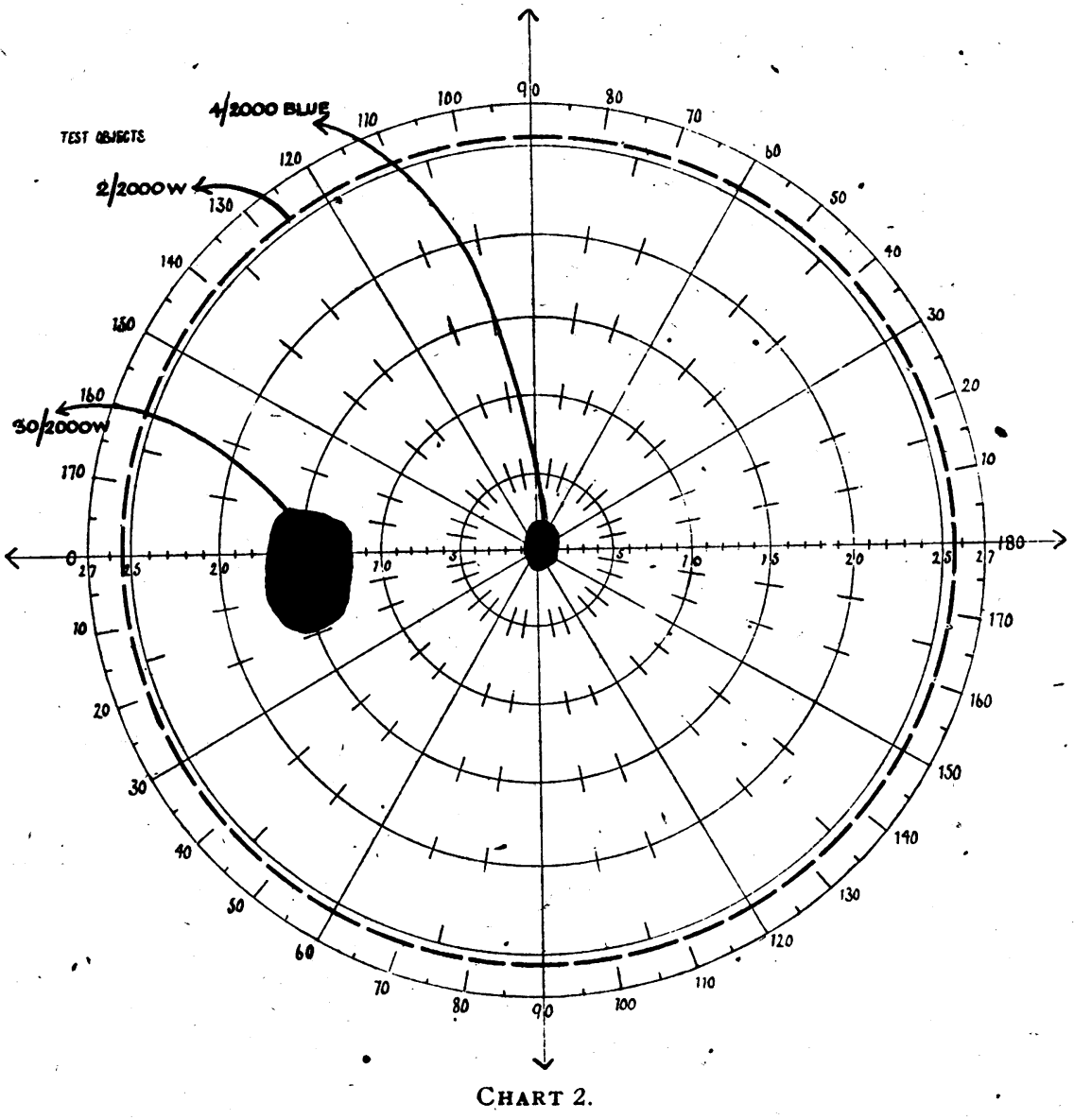

Chart 1. Vision with glasses was :-

R.E. 6/24 first two letters, 6/18 first two letters, 6/12 first two letters, $6 / 9$ second letter only.

The Bjerrum's Screen for the left eye-with white discs showed no abnormality, and vision with glasses was $6 / 6$, the first three letters easily seen and the rest as if seen through some haze.

With blue discs it was possible to demonstrate central scotomata for $4 / 2000$ blue, that of the right eye being the larger (see charts 2 and 3 ). Other isopters for blue were investigated, but no further information obtained. 
Perhaps the papillo-macular bundle has been injured, as mentioned above, in anaemia, but the condition in chart 1 was prob- . ably largely associated with retinal haemorriage.

The cause of the retinal haemorrhages.-(1) Venous obstruction of tributaries was certainly present, but by the time the patient

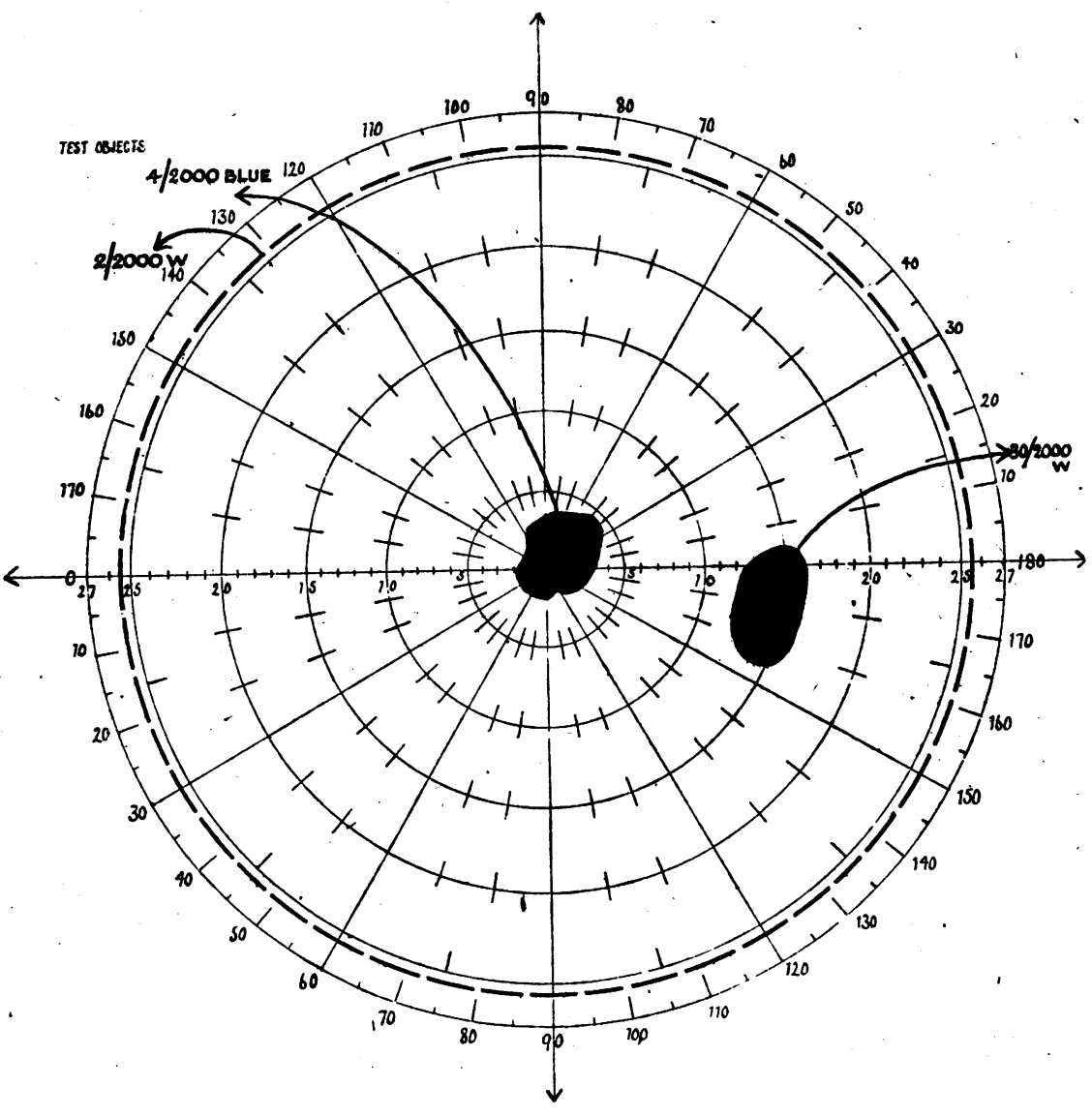

Chart 3.

was seen one did not diagnose bilateral céntral venous thrombosis. It is well to be cautious in making unusual diagnoses, but in this respect compare the case of bilateral occipital thrombosis discussed under hemianopia.

If the diagnosis of bilateral thrombosis of the central retinal vein is accepted it could account for all the retinal haemorrhages.

(2) X-ray treatment. - How far did this cause the haemorrhages by increasing the capillary permeability? It is understood that nasal and similar haemorrhages may follow the X-ray treatment 
and that the danger of their occurrence limits the dosage of $\mathrm{X}$-ray that can be used.

(3) Thrombocytopoinia has been suggested as causing the haemorrhages as much as the $\mathrm{X}$-ray treatment, and that when the thrombocytes begin to rise there is a marked and rapid resolution of haemorrhages.

(4) Subarachnoid haemorrhage has already been considered.

\section{Deduction from this Case}

The various factors involved are not clear; there is ample scope for speculation and suggestion for investigation for workers on vitamins. Some deductions are permissible, such as that vitamin $P$ had a therapeutic effect, but scientific proof by properly controlled experiment is absent.

If vitamin $\mathrm{P}$ had an effect, then it is reasonable to suggest that it might be valuable to use it to prevent haemorrhage when X-ray treatment is being given.

The appended table shows how the general blood picture has steadily improved, and the last two columns show how the capillary permeability has risen. and fallen with the amount of vitamin $\mathrm{P}$ taken by mouth.

\begin{tabular}{|c|c|c|c|c|c|c|c|c|}
\hline $\begin{array}{l}O D L \\
\therefore \quad \text { Date }\end{array}$ & $\begin{array}{c}\text { White } \\
\text { Blood } \\
\text { Corpuscles }\end{array}$ & $\begin{array}{l}\text { Red Blood } \\
\text { Corpuscles }\end{array}$ & Haemoglobin & $\begin{array}{l}\text { Colour } \\
\text { Index }\end{array}$ & Platelets & Reticulocytes & $\begin{array}{c}\text { Capillary } \\
\text { Permeability }\end{array}$ & $\begin{array}{c}\text { Treatment } \\
.\end{array}$ \\
\hline July 26, 1943 & 4,400 & $2,030,000$ & 42 per cent. & 1.0 & - & - & - & 一 \\
\hline Aug., 1943 & - & - & - & - & - & 一 & 一 & $\begin{array}{l}\text { Permidin } \\
\text { 2b.i.d. } 6 / 52\end{array}$ \\
\hline Oct. 7, 1943 & 5,000 & $2,760,000$ & 64 per cent. & $1 \cdot 18$ & 200,000 & 1 per cent. & $450 \mathrm{mgm} . \mathrm{Hg}$. & - \\
\hline Oct. 25,1943 & 7,600 & $3,970,000$ & $\begin{array}{c}78 \text { per cent. } \\
.\end{array}$ & 10 & 280,000 & 1 per cent. & $250 \mathrm{mgm} . \mathrm{Hg}$. & $\begin{array}{c}\text { Rose Hip } \\
\text { Tablets } \\
1 \text { b.i.d. }\end{array}$ \\
\hline Dec. 15,1943 & 6,800 & $3,950,000$ & 88 per cent. & $1 \cdot 1$ & . - & 1 per cent. & $350 \mathrm{mgm} . \mathrm{Hg}$ & $\begin{array}{r}\text { Permidin } \\
1 \text { b.i.d. }\end{array}$ \\
\hline
\end{tabular}

\section{SECOND CASE-General History}

The patient first attended hospital in 1936, and from her doctor it was learned that she had albuminuria and myocarditis, but at the time of operation, 1943, she had no albuminuria. She was not robust and appeared to have had the rather hard-worked life which is the lot of many hospital patients. She was of slow mentality, had sallow skin, some facial hair, and a tired appearance on admission, but her mentality brightened and her skin improved in colour after having vitamin $P$. 


\section{Ophthalmological Notes}

In 1936 she had early cataract in both eyes, more mature in the left eye and vision with glasses was :-

R.E. 6/12 and L.E. 6/24.

The opacities in the left eye progressed most quickly, till in 1943 it was considered well to extract the cataract:

\section{Operation}

On September 14, 1943, a cataract was extracted, with capsulotomy, and a large peripheral iridectomy, but without noteworthy incident, from the eye of a female patient aged 56 , and, after needling, vision with glasses was $6 / 6$ (four letters) on November 23.

\section{Post-operative Complications}

September 17. - Three days after operation there was a hyphaema filling about a third of the anterior chamber.

September 20.- Iris well dilated and blood absorbing.

September 25. - The blood had absorbed, but haemorrhage had occurred again, there was a considerable amount of blood in the anterior chamber, the aqueous was all pink-coloured, and the iris not visible.

September 28.-Absorption seemed to have commenced, the blood occupying only about $1 / 5$ of the anterior chamber.

The iris was visible, but not well dilated and muddy in appearance, and the whole eye looked unhealthy and as if some catastrophe were impending.

One wondered how often this haemorrhage was going to be repeated and what the prognosis was, for it seemed poor.

September 29.-Permidin (Glaxo), 2 tablets b.i.d. was commenced.

September 30 . - The blood was mostly absorbed from the lower part of the anterior chamber, there was less blood in the pupil, the iris was well dilated and bright. The patient herself was much brighter mentally.

October 5. - The anterior chamber was very clear and the clot of blood that had been filling up the pipil was practically absorbed.

October 8.-A spot of pigment about the size of a pinhead remained in the centre of the pupil.

The patient was discharged from hospital and looked much younger and more alert, and her skin had lost its muddy colour and had a more natural and younger appearance.

\section{Comments}

There was post-operative haemorrhage, but when after the second haemorrhage permidin was given, not only did the blood 
at the foot of the anterior chamber quickly absorb, but a clot filling the pupil also rapidly disappeared, and the general condition of the eye and patient improved.

The clot of blood in the pupil when first seen did not look as if it would be readily absorbed under ordinary circumstances, and it seems possible that the vitamin $\mathbf{P}$ given had a beneficial effect on its absorption.

There is no doubt the eye was getting worse till vitamin $\mathbf{P}$ was given, but whether it merely commenced to improve at the same time when vitamin $\mathbf{P}$ was given, or because vitamin $\mathbf{P}$ was given, is not clear.

One thing that is clear is that aftef vitamin $P$ was given the haemorrhage was not repeated and that the eye cleared up and the general health of the patient improved.

Scientific proof of the value of vitamin $P$ is certainly lacking, but it might be permissible to think that the vitamin $\mathrm{P}$ may have been beneficial.

\section{Remarks on both Cases}

In both cases there were ocular haemorrhages, and in the first case other haemorrhages also, and the change after giving vitamin $P$ was dramatic. In both cases vitamin $P$ was given, and in both cases not only did the haemorrhages not recur, but the ocular haemorrhages, the ones that could be actually observed, absorbed very satisfactorily. Moreover, in the first case nasal haemorrhage recurred when vitamin $\mathrm{P}$ was discontinued at one juncture, and in the second case haemorrhage recurred till vitamin $P$ was given, and ceased thereafter.

It is to be noted that the second case was one of cataract, and that it has been suggested in the American Journal of Ophthalmology, 21/1938, pages 1058 and 1059, that deficiency in vitamin $\mathrm{C}$, with consequent defective lens respiration, may be the real cause of cataract, the whole vitamin $\mathrm{C}$ metabolism of the body being deranged in cataract. But the record does not show that any steps were taken to exclude vitamin $P$, which is apparently often found along with vitamin $\mathrm{C}$ in the various natural sources, so that it may be that vitamin $P$ deficiency is a factor in this connection.

In conclusion, it is suggested that there is a case calling for investigation of vitamin $\mathrm{P}$, because, so far as can be judged from the evidence of these two cases, vitamin $P$ is of value in ophthalmology. 